\title{
HÉRNIA INTRA-RAQUEANA DE NÚCLEO PULPOSO GIGANTE. INTERVENÇÃO CIRÚRGICA
}

\author{
Rolando A. Tenuto * \\ Josí: ZaCuIs**
}

Esta publicação tem por finalidade o registro de um caso, interessante sob diversos aspectos, e justifica-se, principalmente, pela exuberância das proporções da peça cirúrgica retirada.

Observação - C. S., branca, com 33 anos de idade. Encontrando-se a pacierte acamada, $\mathrm{em}$ tratamento de insuficiência renal resultante de ingestão acidental de cianeto de mercúrio, apareceu sùbitamente, na região lombai, forte dor, contínua, acentuando-se com os mínimos movimentos da coluna, bem cumo com a tosse e o espirro, não se irradiando. Havia referência vaga a um trauma raqueano ocorrido cêrca de 2 meses antes da instalação da dor, época em que a paciente se encontrava inconsciente em virtude do tóxico ingerido. Como houvesse história pregressa de cólicas hepáticas e tendo o exame radiológico revelado uma colelitíase, foi a paciente submetida a colecistectomia, intervenção que nenhuma influência teve sôbre a dor. A novocainização paravertebral das raízes $L_{\text {: }}$ e $L_{5}$ de ambos os lados também não trouxe qualquer benefício.

O cxame objetivo mostrou paciente com fácies que denotiva sof rimento, imóvel no leito. A dor de que ela se queixava, bem localizada ao nível do $4 .^{\circ}$ e $5 . .^{\circ}$ segmentos lombares, era muito intensificada pela pressão ou percussão sôbre as apófises espinhosas das referidas vértebras. As tentativas de flexão da coluna, assim como as manobras para a pesquisa do sinal de Lasègue, eram frustradas pela acentuada exacerbação da dor que, não obstante, permanecia restrita à parte baixa do segmento lombar. O sinal de Naffziger era negativo. A sensibilidade objetiva era normal.

Tendo sido aventada a hipótese de hérnia de disco intervertebral, foi realizada a perimielografia com Pantopaque, a qual revelou nítida imagem lacunar na margem esquerda da coluna opaca ao nível do espaço intervertebral $L_{4}-L_{5}$ (fig. 1 ).

Confirmado, assim, o diagnóstico de hérnia do disco intervertebral $\mathbf{L}_{4}-\mathrm{L}_{5}$, foi a paciente submetida a nova intervenção cirúrgica. Através de ressecção parcial las lâminas $\mathrm{L}_{4}-\mathrm{L}_{5}$ do lado esquerdo foi vista uma saliência de situação paramediana. Aberto o ligamento longitudinal posterior, foi extraído abundante material, sendo um dos fragmentos de dimensões enormes se comparado com as peças cirúrgicas obtidas nos 112 casos de hérnias de discos intervertebrais que já operamos. A massa total do conteúdo herniário dêste caso era de $10, \tilde{i}$ g (fig. 2).

No dia seguinte ao da intervenção a paciente acusava já acentuado alívio da dor. No $10 .^{9}$ dia do pós-operatório foi colocado colete de gêsso e a doente teve alta hospitalar, pràticamente sem dores.

* Chefe da Seç̧ão de Neurocirurgia no Serviço de Neurologia (Prof. A. To-

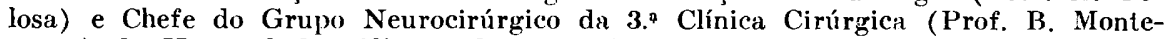
negro) do Hospital das Clínicas da Fac. Med. da Univ. de São Paulo.

* Assistente da Clínica Neurológica da Fac. Med. da Univ. de São Paulo (Prof. A. Tolosa). 

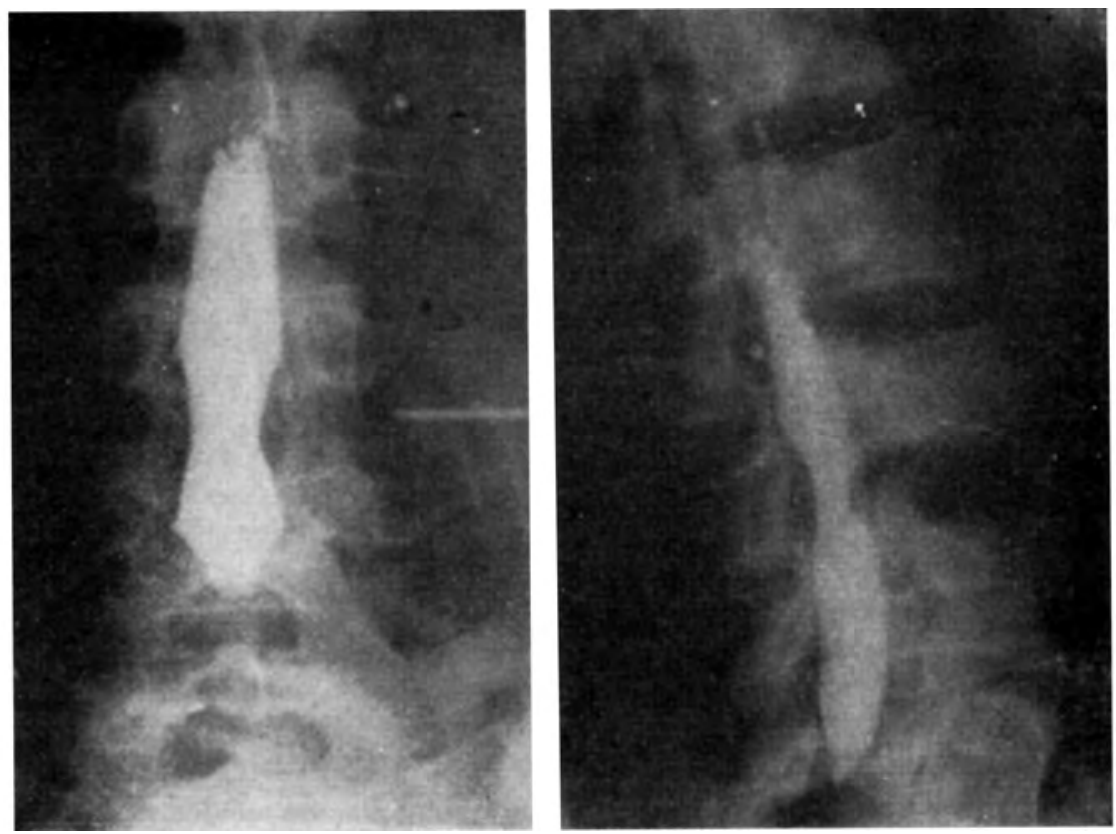

Fig. 1 - Caso C. S. Perimielografia com Pantopaque, mostrando o estrangulanıento da colına de contraste e o alarganento do espaço intervertebral entre $\mathrm{I}_{4} \in \mathrm{L}_{5}$.

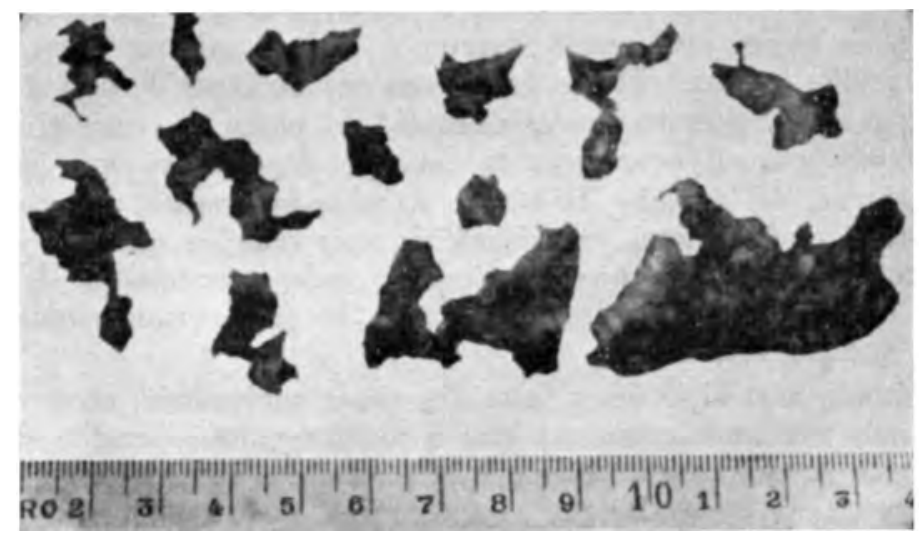

Fig. 2 - Caso C. S. Fragmentos de peça retirada cirùrgicamente. 


\section{COMENTARIOS}

Em primeiro lugar queremos chamar a atenção para o inestimável valor da perimielografia no diagnóstico das hérnias discais, principalmente nos casos em que a hérnia de disco se manifesta apenas por dor lombar, sem ciatalgia. Mesmo nos casos com sintomatologia clássica não prescindimos da confirmação perimielográfica, conduta que não raro nos tem permitido encontrar fàcilmente uma hérnia em nível diferente do que aquêle sugerido pelos elementos clínicos.

E' evidente que não pretendemos atribuir à hérnia de disco intervertebral tôda e qualquer dor lombar, manifestação comum a grande variedade de afecções. Entretanto, diante de uma lombalgia que se manifestou logo após um traumatismo raqueano mais ou menos intenso ou diretamente relacionado a um esfôrço físico maior do que o habitual, essa etiologia deve ser imediatamente lembrada. Em tais casos a perimielografia é, a nosso ver, obrigatória.

Utilizando contraste fluido, como Pantopaque ou Discolipiodol, e retirando a substância radiopaca logo após o exame, conduta que vimos seguindo há algum tempo, é injustificável qualquer temor quanto à instalação de distúrbios secundários da perimielografia, manifestado por alguns especialistas.

A primeira vista, poderia parecer estranho que um núcleo pulposo de proporções exuberantes, fazendo hérnia no canal raqueano, não tenha produzido fenômenos radiculares.

Todavia, tendo em mente que, não obstante o volume exagerado do núcleo pulposo extirpado, a hérnia de disco revelada pela perimielografia e observada durante o ato cirúrgico tinha as dimensões que se observam na maioria dos casos, a não existência de sinais radiculares, deixa de constituir uma raridade. E' inegável que a expressão clínica de hérnia de disco lombar é, na maioria das vêzes, a lombo-ciatalgia. Não é menos verdade, entretanto, que em muitos dêsses casos a ciatalgia só se manifesta após período mais ou menos prolongado, durante o qual os pacientes sentem apenas dores na região lombar. Menos freqüentes são os casos de hérnia de disco lombar que se manifestam exclusivamente, do ponto de vista clínico, por simples lombalgia. A ocorrência da ciatalgia depende, ao que parece, em primeiro lugar, da situação da hérnia e, secundàriamente, de suas dimensões; as de situação lateral, em virtude de suas relações diretas com as raizes nervosas, produziriam sinais radiculares independentemente de suas dimensões, ao passo que as hérnias medianas só produziriam sintomatologia radicular quando volumosas.

Admitindo essa hipótese, a falta dos sinais radiculares, neste caso, fica perfeitamente explicada, uma vez que o abaulamento observado durante o ato cirúrgico se encontrava em situação mediana e não tinha volume suficiente para estirar a raiz $L_{5}$ que se encontrava à sua esquerda.

0 elemento mais importante dêste caso, realmente passivel de discussão, é o volume exagerado do material retirado do interior do disco $\mathrm{L}_{4}-\mathrm{I}_{5}$, se 
comparado com o conteúdo habitual das hérnias de disco intervertebral. Nenhum dado sôbre volume ou massa do núcleo pulposo encontramos nos compêndios de anatomia que pudemos consultar. No livro "Ernia del Disco e Sciatica Vertebrale", Delitala e Bonola referem que o conteúdo herniário mais volumoso por êles encontrado pesava 3 gramas. Não é nosso hábito pesar o material retirado das hérnias de disco, mas, fazendo uma apreciação grosseira, a impressão que temos é que a massa dos mais volumosos conteúdos herniários, nos casos por nós operados, não se afasta muito da cifra encontrada por Delitala e Bonola.

No presente caso, o material retirado do interior do disco intervertebral pesou 10,7 g. Embora, como já dissemos, não conheçamos a massa do núcleo pulposo normal, a peça cirúrgica nos pareceu grande demais para núcleo pulposo. $O$ exame histopatológico mostrou, entretanto, que se tratava de núcleo pulposo com infiltrado inflamatório.

Revendo as chapas radiográficas do caso, observamos, além de lombarização da $1 .^{a}$ vértebra sacra, que as porções adjacentes da $4 .^{a}$ e $5 .^{a}$ vértebras lombares apresentam sinais evidentes de osteoporose e que o espaço intervertebral correspondente, em lugar de estar diminuído, como freqüentemente se observa nos casos de hérnia de disco, é ligeiramente maior do que os espaços vizinhos.

O quadro radiológico é, a nosso ver, incompatível com o resultado do exame histopatológico. Várias hipóteses poderiam ser formuladas para conciliar êsses achados, mas, na falta de uma inteiramente satisfatória, limitamo-nos a registrar o caso.

E' interessante notar que, se as alterações ósseas tivessem sido notadas no início, a perimielografia provàvelmente não teria sido feita, o diagnóstico da hérnia teria escapado e a conduta terapêutica teria sido outra, provàvelmente com prejuízo para a paciente. 